\title{
Circular Economy and Sustainability of the Clothing and Textile Industry
}

\author{
Xuandong Chen ${ }^{1} \cdot$ Hifza A. Memon ${ }^{2} \cdot$ Yuanhao Wang ${ }^{1} \cdot$ Ifra Marriam $^{3} \cdot$ Mike Tebyetekerwa $^{4}(\mathbb{D}$
}

Received: 12 April 2021 / Revised: 22 June 2021 / Accepted: 22 June 2021 / Published online: 6 July 2021

(c) The Author(s), under exclusive licence to Springer Nature Singapore Pte Ltd. 2021

\begin{abstract}
Textiles are essential to humans in a variety of ways, especially clothing. However, the speed at which they end up in landfills is astonishing (one garbage truck per second), posing a severe risk to the environment, if the trend continues. Governments and responsible organizations are starting to make calls to different stakeholders to redesign the textile chain from linear to circular economy. In this perspective, we highlight some of the possible approaches to be undertaken including the need for the creation of renewable raw materials sources, rethinking production, maximum use and reuse of textile products, reproduction, and recycling strategies, redistribution of textiles to new and parallel markets, and improvising means to extend the textiles lifetime.
\end{abstract}

Keywords Circular economy $\cdot$ Sustainability $\cdot$ Clothing $\cdot$ Textile $\cdot$ Pollution $\cdot$ Fashion

\section{Introduction}

Fashion quenches the thirst of its demand coming from consumers with at least a new "collection" every week (Stanton 2018). Global clothing consumption is $400 \%$ more than the amount consumed two decades earlier (Jia

Xuandong Chen and Hifza A. Memon contributed equally toward this work

Yuanhao Wang

326369854@qq.com

Mike Tebyetekerwa

mike.tebyetekerwa@anu.edu.au

1 College of Civil and Architecture Engineering, Guangxi Key Laboratory of New Energy and Building Energy Saving, and Guangxi Engineering Research Center for Solid Waste Resources Development and Application, Guilin University of Technology, Guilin 541004, People's Republic of China

2 Department of Textile Engineering, Mehran University of Engineering and Technology, Sindh 76062 Jamshoro, Pakistan

3 School of Mechanical, Medical, and Process Engineering, Queensland University of Technology (QUT), 2 George St, Brisbane, QLD 4000, Australia

4 School of Engineering, College of Engineering and Computer Science, The Australian National University, Canberra, ACT 2601, Australia et al. 2020; Shirvanimoghaddam et al. 2020). The growth in consumption dictates the amount of energy utilized in running production, the number of materials in circulation, and handling means of the materials during usage, which all seem detrimental to the environment (Chae and Hinestroza 2020; Sadeghi et al. 2021). Textile production is the world's second most polluting industry second to the oil industry accounting for approximately 1.2 billion tons of greenhouse gas emissions (more than for international flights and maritime shipping combined) (Change 2018). By 2050 it is anticipated that the fashion industry will use up to 25\% of the world's carbon budget (Pandey 2018). There is an urgent need to tackle the adverse effects of the fashion industry for sustainability through circular economy approaches (Saha et al. 2021).

In this perspective, we highlight some of the approaches the textile and clothing industry can adopt to overcome the challenges it is facing, for its survival in the new, strict, and upcoming green circular economy which requires maximum use of resources with little or no waste, with zero emissions, but still able to make profits without harming the environment. First, we briefly reveal the state and wastefulness of the textile and clothing industry by describing the following; the effect of fast fashion, fiber production, and water consumption together with pollution. Second, we explore how the current linear economy of the textile and clothing industry can be changed to a circular economy by individually 
focusing on raw materials, products, use, and after-use activities. In the final section, a conclusion and detailed outlook is provided summarizing the key issues discussed in the article.

\section{State of the clothing and textile industry}

The current state of the fashion, clothing, and textile industry is worrying in the space of sustainability. Most of the raw materials employed and the resultant products (fibers and clothing) are harmful to the environment. Fast fashion is highlighted below to accelerate the rate at which the textile products pour into the environment and at the same time quickly kills the time duration the products stay in use. Fiber production has been reckoned to recently focus much on non-biodegradable synthetic fibers, albeit with chances of recycling and reuse due to their unique chemical structures. Also, huge amounts of water consumption and pollution especially for and from textile wet processing operations of dyeing, finishing, sizing and other similar processes is a major concern to sustainability. The provided accounts below are a summary of the current state of the clothing and textile industry. These ideas have already been coined in recent review articles with much more depth. The articles/book chapters by Jia et al. (2020); Moorhouse and Moorhouse (2017); Saha et al. (2021); Shanmugam et al. (2020); Shirvanimoghaddam et al. (2020) are recommended to the readers who wish to get a much detailed account of the ideas below.

Fast fashion Recently, there exists many cheap and trendy clothing which are low-level (quality) samples of ideas from high-end culture and celebrity ideas being featured at relatively affordable prices as a means to quench the demand amongst low-income earners. This is what is referred to as "fast fashion". Fast fashion accelerates the number of clothing purchased globally given the fact it happens when the demand is high and at low prices. Many well-known fast fashion brands such as, H\&M and Zara, manufacture clothes that are quickly replenished as they travel through the wardrobes into the bins at a fast pace. To this day, the world consumes about 80 billion new clothing every year (Firth 2016; Yoo et al. 2021). Statistically, an average American generates $82 \mathrm{lb}$ of textile waste each year, and the USA alone dumped (landfills or burned) close to 14 million tons of textile waste in 2018 with only 2.5 million tones recycled (Fig. 1A) (EPA 2021). Globally, 92 million tons of textile waste is generated per year with 134 million tons per year expected by the end of 2030 (Kerr and Landry 2017). All these figures are driven by the presence of cheap clothing courtesy of fast fashion. Besides cost, fast fashion realizes low-quality clothing at very high production speed. These contents of fast fashion such as high production, low quality, and competitive pricing pose a negative impact on the environment, resources and people involved (both in production and consumption). Therefore, there is need to control fast fashion, towards non wasteful and green economy (Moorhouse and Moorhouse 2017).

Fiber production The global fiber production reached 111 million metric tons in 2019, which has doubled in the last 20 years (Shirvanimoghaddam et al. 2020), with pre-COVID-19 results indicating potential growth to 146 million metric tons by 2030 (Worley 2020). Fibers used in clothing can be subdivided into two major categories; natural and synthetic fibers. Natural fibers are those that exist in nature such as cotton, wool, sisal, silk, and others, whereas synthetic fibers include fibers like polyester, nylon, acrylic, and others. Fiber production nowadays is dominated by synthetic fibers $(\sim 69 \%)$ with the rest shared between natural fibers and blends of natural and synthetic fibers (Fig. 1B). It is estimated that around 98\% of all future fibers will be synthetic, $95 \%$ of which is expected to be polyester (Qin 2014). The rise in synthetics poses an environmental concern due to many reasons in various perspectives (Young 2019). (1) The production of synthetic polymers is estimated to utilize 98 million tons of oil globally each year which can be used directly as fibers, dyes, and finishes hence dependent on fossil fuel extraction (Morlet et al. 2017). (2) Synthetic fibers are nonbiodegradable. They can stay in the environment for many years. (3) Also, given that fibers are small (micron size), they are more detrimental than centimeter-scale plastics. For example, washing synthetic clothing tends to nano and microfibers into waterways causing immeasurable damage to marine life and vital ecosystem and cannot easily be traced (Young 2019). (4) The energy (Table 1) used and the resultant $\mathrm{CO}_{2}$ emission as a result of obtaining synthetic fibers is much higher as compared to natural fibers (Table 2) (OEcotextiles 2011).

Water consumption and pollution The clothing cycle (production to usage) is currently wasteful and polluting (Fig. 1C). Fiber production, clothing production, use, and after use all consume an enormous amount of water and leaves traces of fibers and chemicals in water sources. The annual textile production consumes approximately 93 cubic meters of water per year (Berger et al. 2021; Morlet et al. 2017), which is equivalent to 37 million Olympic swimming pools. And, individually to make just one cotton T-shirt, it takes approximately 27201 of water equivalent to what one adult would drink in three years (Chan 2020). The water consumption continues even during the different usage cycles in the form of cleaning. This high consumption can easily be felt in regions with less 


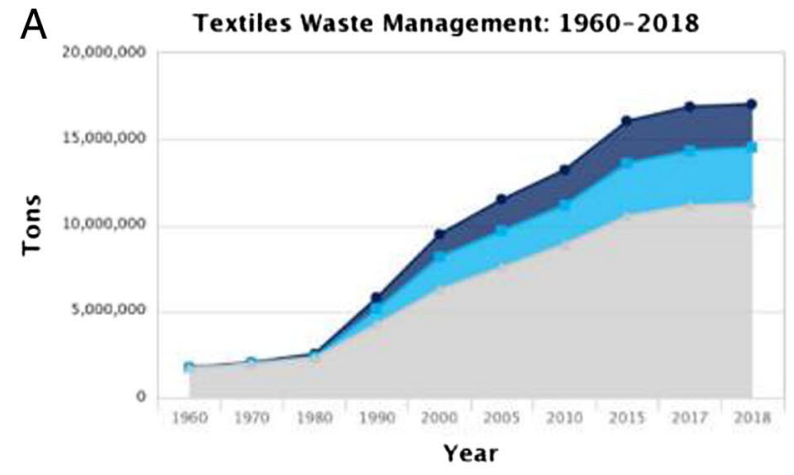

Recycled Composted

C

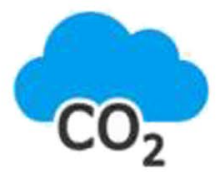

\section{Recycling} Dumping

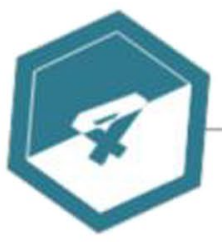

After Use

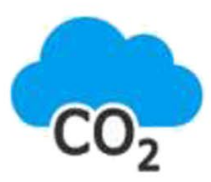

Transport Washing

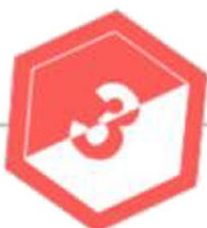

Logistics and Use
B Million Metric Tons
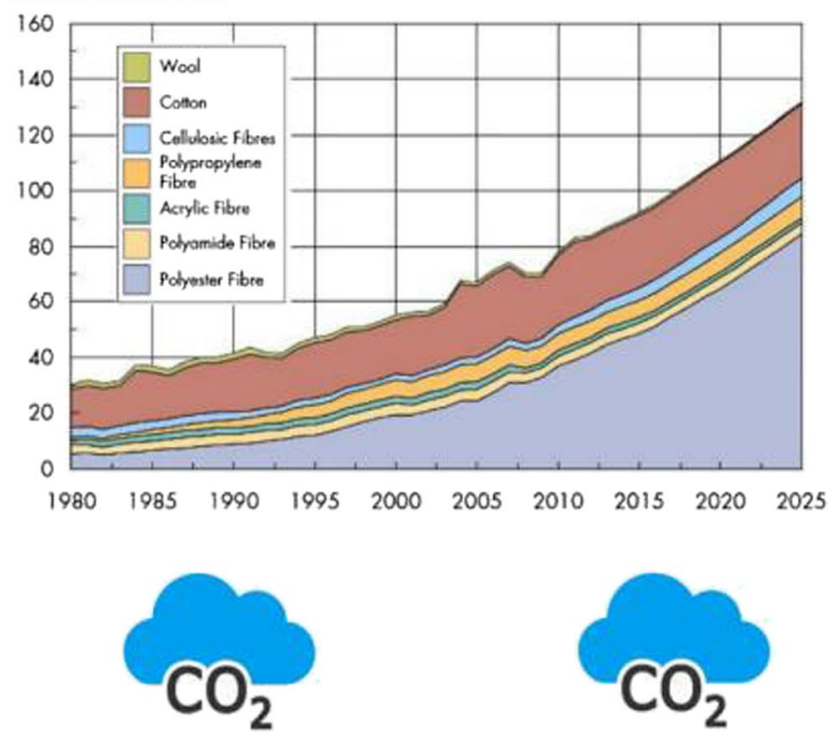

Wet processing Sizing

Oil sources

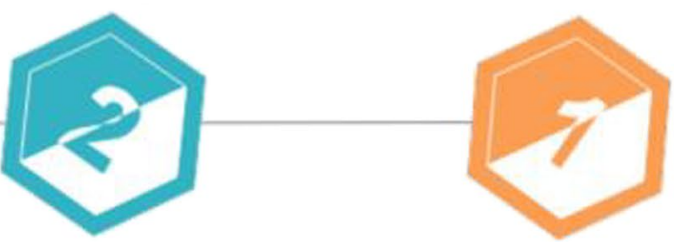

Clothing Industry
Fig. 1 State of the clothing industry. (A) The dynamics of textiles waste management in the USA from 1960 to 2018. In 2018, approximately 2.5 million tons of textiles were recycled, 3.2 million tons combusted and 11.3 million tons ended up in landfills. (Source: American Apparel and Footwear Association, International Trade Commission, the U.S. Department of Commerce's Office of Textiles and Apparel, and the Council for Textile Recycling). Image repro-

water. More still, the textile industry is estimated to be responsible for $20 \%$ of global water pollution as a result of dyeing and finishing during production (Kant 2012). Moreover, fiber production and clothing production usually takes place in developing countries. Later the manufactured clothing are transported to developed countries. The logistics alone are not sustainable.

In a nutshell, sustainability and circular economy in the clothing and textile industry is loudly called for due to the industry's wasteful and polluting linear economy as explained above. The industry practices include damping and fast accumulation of wastes leading to adverse duced from Reference (EPA 2021). (B) Global fiber production with synthetic fibers taking up at most $75 \%$ of which close to $55 \%$ is polyester in 2020 (Source: OrbiChem). Image reproduced with permission. (C) Major activities in the fashion and clothing industry responsible for most emissions. From fiber production, clothing production through to use, and after use high amounts of pollutants are released to the environment

environmental effects such as micron synthetic fibers ending up in water streams and consequently human bloodstream which is detrimental to our health. In addition, the industry's extensive water usage and pollution from dyes and fibers are harmful to both environment and living organisms. Yet the products (clothing) produced with such wasteful approaches are only used for a limited time, and not recycled but dumped/landfilled in the environment. Having reviewed the state of the clothing industry, its activities, and their impact on the overall sustainability of the environment, it is now important to understand ways to mitigate these problems. 
Table 1 Energy consumption needed for the production of various polymeric fibers. ( Source: Barber and Pellow)

\begin{tabular}{ll}
\hline Polymer/fiber & $\begin{array}{l}\text { Energy consumption } \\
\text { (MJ/kg of fiber) }\end{array}$ \\
\hline Natural polymers & \\
$\quad$ Flax & 10 \\
Cotton & 55 \\
$\quad$ Wool & 63 \\
Synthetic polymers & \\
$\quad$ Viscose & 100 \\
Polypropylene & 115 \\
Polyester & 125 \\
Acrylic & 175 \\
Nylon & 250 \\
\hline
\end{tabular}

Table 2 Total $\mathrm{CO}_{2}$ emissions per ton spun fiber ( Source: Stockholm Environment Institute)

\begin{tabular}{llll}
\hline Fiber/polymer & Crop cultivation & Fiber production & Total \\
\hline Polyester, USA & 0.00 & 9.52 & 9.52 \\
Cotton, conventional, & 4.20 & 1.70 & 5.90 \\
$\quad$ USA & & & \\
Hemp, conventional & 1.90 & 2.15 & 4.05 \\
Cotton, organic, India & 2.00 & 1.80 & 3.80 \\
Cotton, organic, USA & 0.90 & 1.45 & 2.35 \\
\hline
\end{tabular}

\section{Circular economy}

The current clothing system in regards to manufacturing, distribution, and usage of clothing operates in an almost entirely linear way (Fig. 2). Over $68 \%$ of current fibers are extracted from non-renewable resources such as fossil fuels to make clothes (with polluting processes) which are used for a very short time, which later are dumped in landfills or incinerated. Over $\$ 183$ million worth of clothing goes into landfills each year (Wrap 2020). Such a linear system leaves many economic opportunities untapped, pollutes and degrades the environment, possesses pressure on scarce resources, and strains the economics of the societies. There is an urgent need to switch from such a linear economy to a circular economy to address the challenges (Gardetti 2019). The circular economy is briefly driven by 3 major activities and approaches (Fig. 2) i.e. reduce, reuse, and recycle, which are all typical approaches of traditional waste management (Manickam and Duraisamy 2019). Reduction broadly involves waste reduction at all the steps of production (including minimal raw materials usage) and different stages of consumption and use. Reuse in this space entails rethinking production to obtain products that can be easily recycled or repurposed for a variety of other applications. Ultimately, increased reuse and repurposing will mitigate the increased need for production.
Fig. 2 Key differences between linear and circular economy
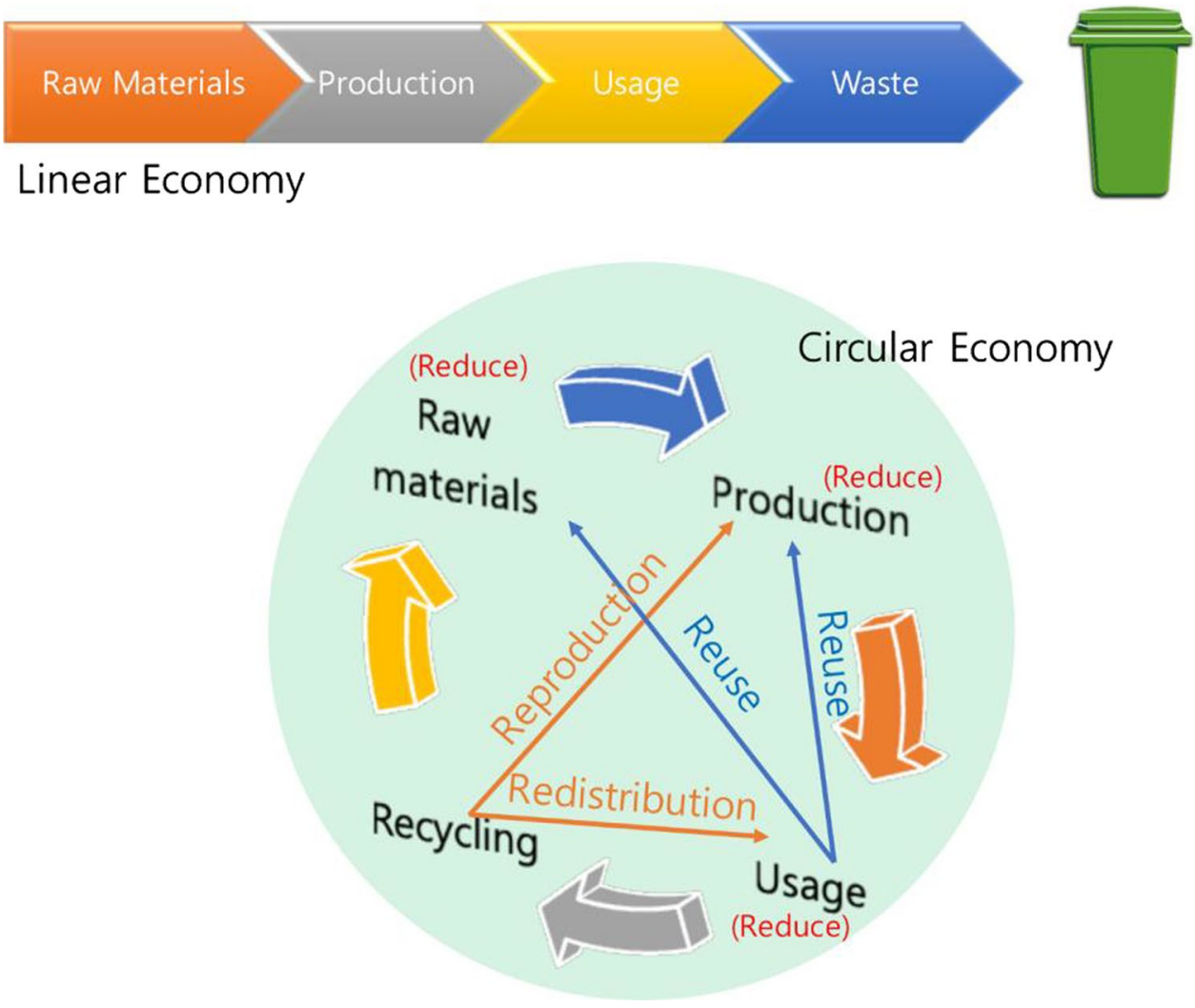
The economic value of the circular economy is obvious, and in terms of monetary value, it is estimated that the world economy could be improved by $\$ 192$ billion by 2030 if the fashion industry addresses the problems presented by its current linear economy (Morlet et al. 2017). Some of the critical activities facilitating circular economy include: creating renewable sources, rethinking production, maximum use and reuse, reproduction, and recycling, redistribution to new and parallel markets, extending product lifetime, and many others (Kumar and Saravanan 2019). Beyond these activities, recent excellent reviews from (Jia et al. 2020) and (Shirvanimoghaddam et al. 2020) are referred to the readers for a broad knowledge of the recent literature surveys, drivers, barriers, practices, and indicators of sustainable performance when applying a circular economy in the textile and apparel industry. An important article by (Jacometti 2019) also attempted to highlight the Euopean Union revised legislative framework on the circular economy action plan of 2015 and could be of importance to the reader.

\section{Recycling clothing}

Getting fibers back to the circular loop Fibers make almost $98 \%$ of finished clothing. The $73 \%$ of fibers used in clothing ends up either in landfill or an incinerator with only 12\% recycled (Morlet et al. 2017). Fibers are small and are exposed to rough processes during recycling which damages their quality, and thus only $1 \%$ of the recycled fibers can be utilized again in clothing. Most of the recycled fibers can only be used in other functions such as cleaning cloths, carpets, mattress stuffing, and related functions, which itself is a challenge as the quality is lost (Notman 2020). However, as a solution, new fibers can be readily blended with old recycled fibers to strike the right balance between quality and sustainability. In the case of synthetics, such as polyester, the fibers can be chemically broken down to their chemical building blocks and later melt-spun into new fibers with exactly similar properties as the new virgin fibers entering the circular loop. This strategy has two main challenges: (1) Sorting and (2) economics. On the economics, chemical fiber recycling has proven to be expensive, resulting in fibers that are far expensive than considering new virgin fibers. Sorting is a challenge because clothes are usually made of blends, say natural and synthetic fibers or synthetic/synthetic blend with different properties which can be hard to separate to break the individual fibers in its chemical building blocks. On an extended note, blending in textiles can happen at the fiber level, yarn level, and fabric level. These different levels pose the recycling department with new strategies to effect sorting before recycling. Some sorting challenges can be innovatively solved, as described in the next paragraphs. Overall, it is simplistic to state that clothing are easy to recycle. The fact is that clothes are complex to recycle (Beall 2020). In this sense, chemists, environmental scientists, textile technologists, and policymakers need to innovatively think of several realistic approaches to overcome the involved challenges with recycling.

\section{Sorting as one of the key challenges}

RFID tags. Radio Frequency Identification (RFID) tags (Fig. 3A) can be employed to sort clothes at a fabric level. They are added to fabric hems during garment production and are capable of remaining active during the whole process of clothing use. Sorting with the help of RFID tags uses the same approach employed by the infrared sensors for automated systems in plastic sorting industries. Beyond, sorting capabilities, with RFID tags, the manufacturer can track the clothing within and out of the store and are sources of big data to the manufacturer to monitor product use and later collection after use. To customers, they facilitate fast self-checkouts in stores and are capable of communicating with smart washing machines for optimum washing settings. However, many customers worry about privacy and health concerns with technology.

Solvent technologies At the fiber and yarn level, RFID tags cannot be employed to sort materials, but solvent technologies (Fig. 3B) can be readily employed. Solvent technologies can be subdivided into two as follows: (1) Dissolving the dissolvable and remain with the undissolvable and (2) hightemperature heating which dissolves one fiber and leaves the other fiber behind as solid. The earlier approach is based on the one material being able to dissolve and others not. For example, cotton/polyester fibers in fabrics can be sorted by dissolving cotton cellulose in a solvent and then leaving polyester behind. The cellulose dissolved can be used to make new synthetic fibers with natural recycled sources as in the case of Lyocell, Rayon, Cupro, and Acetate fibers. Also, if the quality is not great, it can be used to make pulp and paper. These approaches are sustainable and the backbone of the circular economy. On the other hand, the latter approach depends on the melting temperature difference (higher difference) of the fibers to be sorted. For example, A/B fibers can be sorted by first swelling the two fibers at high temperatures to release the organic dye molecules and other contaminants. At a specific temperature, A will start to melt, but $\mathrm{B}$ will remain behind as a solid. Which are then filtered for separation, and proceeded for recycling. Scaling up these technologies is still a challenge but are key solutions to avoiding a linear clothing economy.

Biosorting This concept attempts to utilize living organisms or enzymes to consume part of the fibers and leaving behind the other. Beyond biosorting, bio recycling is possible in 
Fig. 3 Sorting of fibers and fabrics before recycling. (A) Left: RFID yarn that can be woven into garment seams which can later be employed during the fabric sorting process (Source: (c) Adetex). Right: Clothing label with RFID incorporated. (B) Fiber and yarn sorting can be done using physical and chemical solvent techniques

A Fabric level sorting
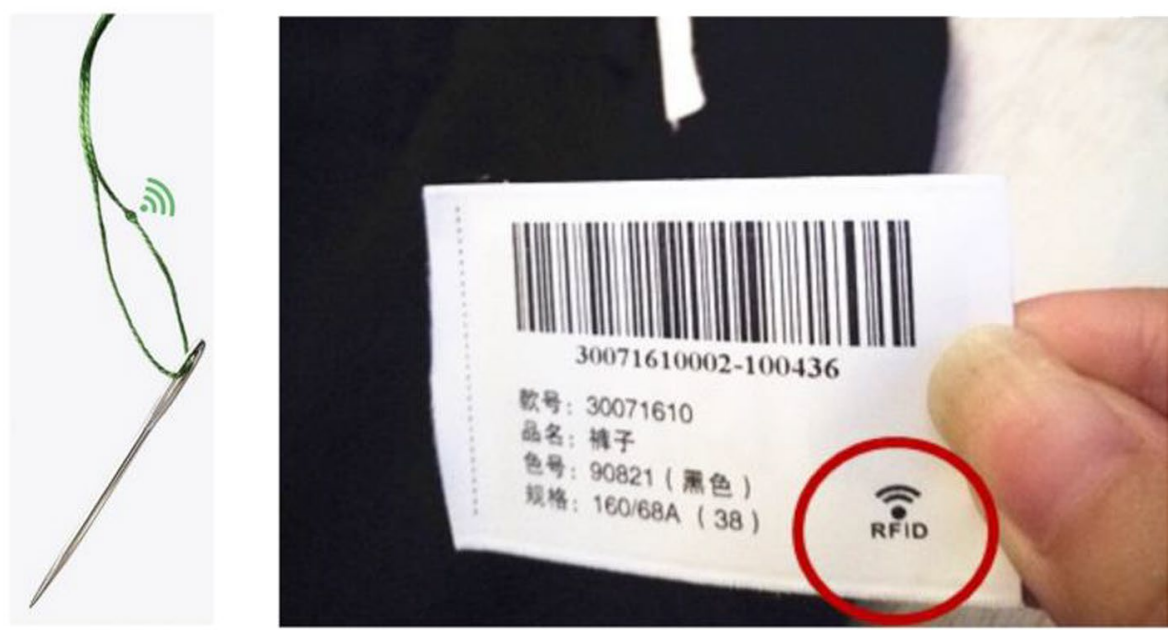

Fiber/yarn level sorting

Dissolved cellulose can be used to make paper and pulp

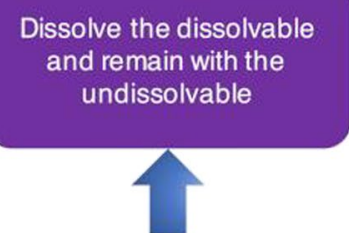

Mechanicalremoval of zips, buttons and other accessories
Washing to remove dyes and other related chemicals

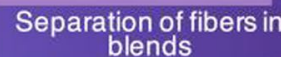
blends

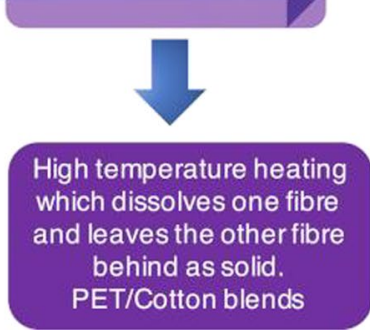

High temperature heating which dissolves one fibre and leaves the other fibre behind as solid.

PET/Cotton blends which the enzymes depolymerize textile waste fibers into their original monomers (Burik 2018). In this approach, sorting can be bypassed, decreasing the overall costs.

\section{Reuse and repurpose of clothing}

Reusing and repurposing clothes are essential activities in facilitating a circular economy. Some countries (such as Germany) have high collection rates of textiles for reuse to a tune of $75 \%$ of textiles (Morlet et al. 2017) which are usually exported to low-developing countries for extended use. However, in the countries where second-hand clothing are exported, similar collection infrastructures do not exist and thus used clothing there will end up in landfills (Watson et al. 2016). The whole system is like delegation of responsibility to an incompetent society, which in turn is an environmental
Sometimes swelling in done for synthetics to release impurities and dyes concern. One of the solutions is to repurpose the clothing to new uses.

\section{Resale and rental approach}

It was estimated that $\$ 460$ billion could be added to clothing consumer pockets annually if they decided not to throw their clothing in the bins (Morlet et al. 2017). On average consumers discarded their clothing after just seven to ten wears (Armour 2015; Morgan and Birtwistle 2009). Through the resale and rental approach clothing use can be extended, which can slash the environmental impact of clothing. However, telling people to buy less and wear what they do buy more often seems not to be a viable approach due to the different psychological and societal needs of individuals. There is an increased effort needed to make this a reality through various environment teaching and learning programs. Moreover, with the resale and 
rental program capable of adding some dollars to the customers' pockets, the success rate is relatively high.

\section{Conclusions and outlook: the new clothing and textile circular economy}

The ambitions of the new circular economy aim at reinventing and bending the linear economy to more sustainable approaches. This can be focused on four major parts of the clothing system wheel as follows; (1) materials, (2) production, (3) usage, and (4) after usage. In all sections, enormous innovation is paramount given the fact the textile industry is an old industry whose processes can hardly be changed which can take place in the form of; (1) phasing out of substances of concern and microfiber release, (2) increasing clothing utilization, (3) improving recycling and (4) making effective use of resources and migration to renewable inputs as illustrated in Fig. 4.

In the different stages, the following can be done;

1) Materials: The raw materials for textiles should be made renewable, or easily recyclable with little or no concerns to the environment. The best approach can be to use big data material informatics (Jose and
Ramakrishna 2018; Tebyetekerwa et al. 2019) to search for options of replacement. Concerns about the small, untraceable fiber plastics can be solved by using biodegradable fibers. Also, efforts and policies should be made to ensure all staple fibers are made from biodegradable materials, and filaments that can be easily collected from the environment can either be made degradable or biodegradable.

2) Production: Renewable energy should be used to run production machinery which should also be designed to be energy-efficient. Intensive energy processes requiring high volumes of water with high pollution such as wet processing during dyeing can be replaced with printing and use of naturally derived dyes or low-temperature synthetic dyes in single big batch dyeing processes. Also, care should be taken to treat the effluents before disposal and never in the natural water stream.

3) Usage: This is aimed at increasing clothes usage with less environment. Short term usage can be controlled by resale and rental approaches. Fast fashion can be discouraged to target durable clothing with higher quality enabling long term use through brand commitment and policy. Modern designs with anti-soiling effects can be promoted, which need less washing, hence saving

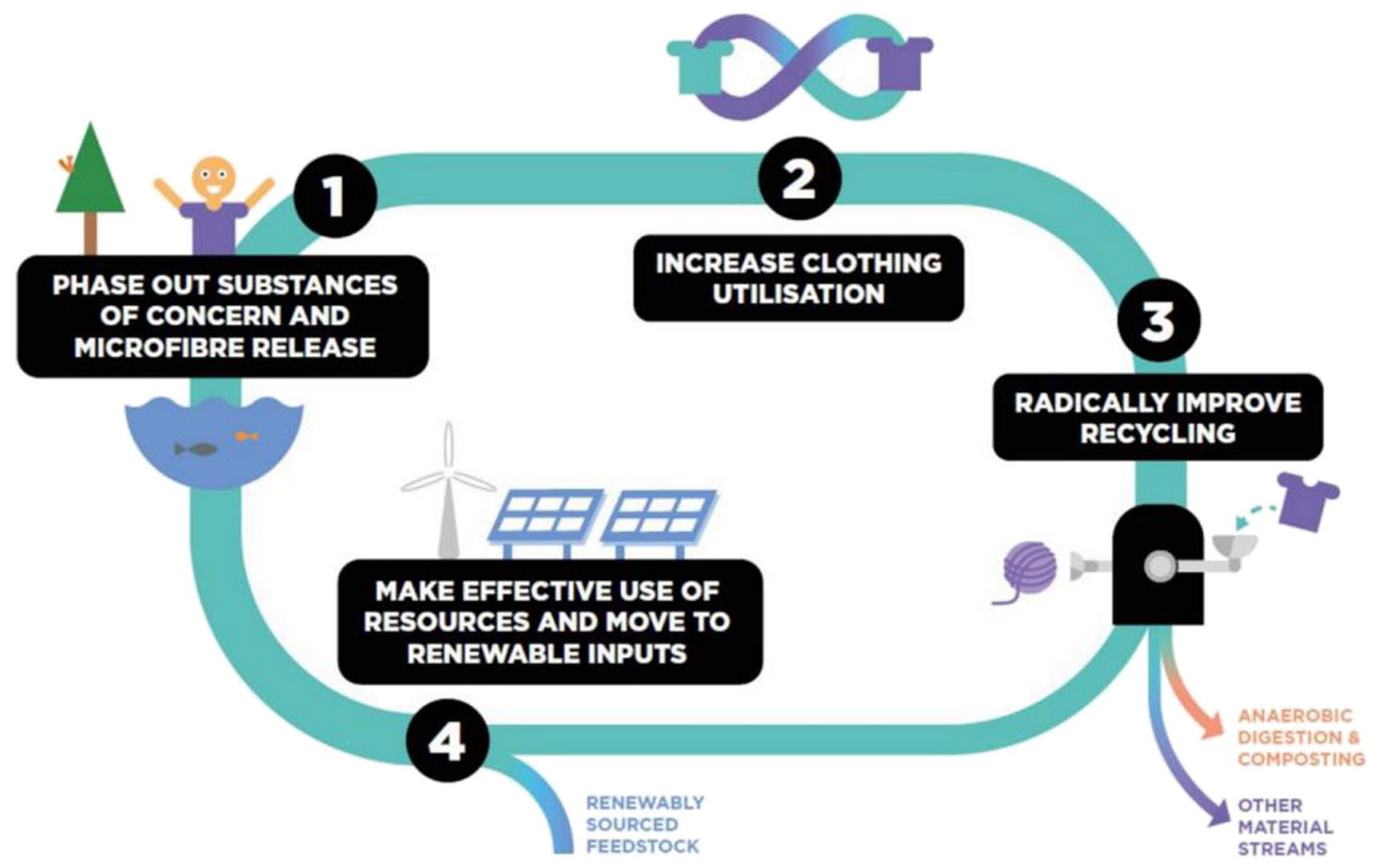

Fig. 4 The ambitions of the proposed clothing circular economy. Figure reproduced with permission from Reference (Morlet et al. 2017) 
water, greenhouse gases emissions and fibers/dyes coming from the cleaning process to the water stream.

4) After usage: It incorporates technologies such as RFID to facilitate the collection, sorting, recycling and reprocessing. Rethink recycling technologies to make them cheaper and affordable.

\section{Declarations}

Conflict of interest The authors declare no competing interests.

\section{References}

(EPA) USEPA (2021) Facts and figures about materials, waste and recycling: textiles: material-specific data. Available from https://www. epa.gov/facts-and-figures-about-materials-waste-and-recycling/texti les-material-specific-data. Accessed 17 May 2021

Armour R (2015) Once worn thrice shy - women's wardrobe habits exposed. Available from https://thirdforcenews.org.uk/tfn-news/once-wornthrice-shy-womens-wardrobe-habits-exposed. Accessed 01 Aug 2020

Beall A (2020) Why clothes are so hard to recycle. BBC Future, Available from https://www.bbc.com/future/article/20200710-why-cloth es-are-so-hard-to-recycle. Accessed 01 Aug 2020

Berger M, Campos J, Carolli M et al (2021) Advancing the water footprint into an instrument to support achieving the Sdgs - recommendations from the "Water as a Global Resources" Research Initiative (Grow). Water Resour Manag 35:1291-1298. https://doi.org/10. 1007/s11269-021-02784-9

Burik A (2018) We can now make plastics out of old clothes using biology. Labiotech.eu, Available from https://www.labiotech.eu/indus trial/carbios-plastic-textile-waste-enzymes/. Accessed 01 Aug 2020

Chae Y, Hinestroza J (2020) Building circular economy for smart textiles, smart clothing, and future wearables. Mater Circ Econ 2:2. https:// doi.org/10.1007/s42824-020-00002-2

Chan E (2020) The fashion industry is using up too much water - here's how you can reduce your H2o Footprint. Vogue. Available from https:// www.vogue.com.au/fashion/news/the-fashion-industry-is-using-uptoo-much-water-heres-how-you-can-reduce-your-h2o-footprint/newsstory/bdfea09belee1f28de0f32bfc10a71d4. Accessed 01 Aug 2020

Change NC (2018) The Price of fast fashion. Nat Clim Chang 8:1-1. https://doi.org/10.1038/s41558-017-0058-9

Firth L (2016) The True Cost. Available from https://truecostmovie.com/ learn-more/environmental-impact/. Accessed 01 Aug 2020

Gardetti MA (2019) 1 - Introduction and the concept of circular economy. In: Muthu S. S. (ed) Circular Economy in Textiles and Apparel. Woodhead Publishing, Cambridge, pp 1-11. https://doi.org/10.1016/ B978-0-08-102630-4.00001-7

Jacometti V (2019) Circular Economy and Waste in the Fashion Industry. Laws $8: 27$

Jia F, Yin S, Chen L, Chen X (2020) The circular economy in the textile and apparel industry: a systematic literature review. J Clean Prod 259:120728. https://doi.org/10.1016/j.jclepro.2020.120728

Jose R, Ramakrishna S (2018) Materials 4.0: Materials big data enabled materials discovery. Appl Mater Today 10:127-132. https://doi.org/ 10.1016/j.apmt.2017.12.015

Kant R (2012) Textile Dyeing industry an environmental hazard. Nat Sci 04:22-26. https://doi.org/10.4236/ns.2012.41004

Kerr J, Landry J (2017) Pulse of the fashion industry. Global Fashion Agenda, The Boston Consulting Group, Boston. https://www.globa lfashionagenda.com/publications-and-policy/pulse-of-the-industry. Accessed 01 Aug 2020

Kumar PS, Saravanan A (2019) 7 - Sustainable business strategies and circular economy. In: Muthu S. S. (ed) Circular Economy in Textiles and Apparel. Woodhead Publishing, Cambridge, pp. 149-167. https://doi.org/10.1016/B978-0-08-102630-4.00007-8

Manickam P, Duraisamy G (2019) 4 - 3rs and circular economy. In: Muthu S. S. (ed), Circular Economy in Textiles and Apparel. Woodhead Publishing, Cambridge, pp. 77-93. https://doi.org/10.1016/ B978-0-08-102630-4.00004-2

Moorhouse D, Moorhouse D (2017) Sustainable design: circular economy in fashion and textiles. Des J 20:S1948-S1959

Morgan LR, Birtwistle G (2009) An investigation of young fashion consumers' disposal habits. Int J Consum Stud 33:190-198. https://doi. org/10.1111/j.1470-6431.2009.00756.x

Morlet A, Opsomer R, Herrmann S, Balmond L, Gillet C, Fuchs L (2017) A new textiles economy: redesigning fashion's future. Ellen $\mathrm{MacAr}-$ thur Foundation. https://www.ellenmacarthurfoundation.org/assets/ downloads/publications/A-New-Textiles-Economy_Full-Report.pdf. Accessed 01 Aug 2020

Notman N (2020) Recycling clothing the chemical way. Chemistry World. Available from https://www.chemistryworld.com/features/recyclingclothing-the-chemical-way/4010988.article. Accessed 01 Aug 2020

OEcotextiles (2011) Estimating the carbon footprint of a fabric. Available from https://oecotextiles.wordpress.com/2011/01/19/estimating-thecarbon-footprint-of-a-fabric/. Accessed 01 Aug 2020

Pandey K (2018) Fashion industry may use quarter of world's carbon budget by 2050. Available from https://www.downtoearth.org.in/ news/environment/fashion-industry-may-use-quarter-of-world-scarbon-budget-by-2050-61183. Accessed 01 Aug 2020

Qin Y (2014) Global fibres overview, synthetic fibres raw materials committee meeting at apic, pattaya, 16 May 2014. Available from http:// www.orbichem.com/userfiles/APIC\%202014/APIC2014_Yang_ Qin.pdf. Accessed 01 Aug 2020

Sadeghi B, Marfavi Y, AliAkbari R, Kowsari E, BorborAjdari F, Ramakrishna S (2021) Recent studies on recycled pet fibers: production and applications: a review. Mater Circ Econ 3:4. https://doi.org/10. 1007/s42824-020-00014-y

Saha K, Dey PK, Papagiannaki E (2021) Implementing circular economy in the textile and clothing industry. Bus Strateg Environ 30:14971530. https://doi.org/10.1002/bse. 2670

Shanmugam V, Das O, Neisiany RE et al (2020) Polymer recycling in additive manufacturing: an opportunity for the circular economy. Mater Circ Econ 2:11. https://doi.org/10.1007/s42824-020-00012-0

Shirvanimoghaddam K, Motamed B, Ramakrishna S, Naebe M (2020) Death by waste: fashion and textile circular economy case. Sci Total Environ 718:137317. https://doi.org/10.1016/j.scitotenv.2020.137317

Stanton A (2018) What is fast fashion, anyway? Available from https:// www.thegoodtrade.com/features/what-is-fast-fashion. Accessed 01 Aug 2020

Tebyetekerwa M, Marriam I, Xu Z et al (2019) Critical insight: challenges and requirements of fibre electrodes for wearable electrochemical energy storage. Energ Environ Sci 12:2148-2160. https://doi.org/ $10.1039 / \mathrm{c} 8 \mathrm{ee} 02607 \mathrm{f}$

Watson D, Palm D, Brix L, Amstrup M, Syversen F, Nielsen R (2016) Exports of Nordic used textiles: fate, benefits and impacts. Nordic Council of Ministers. http://norden.diva-portal.org/smash/record. jsf?pid=diva2\%3A1057017\&dswid=1049. Accessed 01 Aug 2020

Worley D (2020) Textile exchange's 2020 preferred fiber and materials market report (Pfmr). Available from https://textileexchange.org/wp-content/ uploads/2020/06/News-Release-Textile-Exchange-Releases-2020-Prefe rred-Fiber-and-Materials-Market-Report.pdf. Accessed 01 Aug 2020

Wrap (2020) Clothing: Wrap. Available from http://www.wrap.org.uk/ content/clothing-waste-prevention. Accessed 01 Aug 2020 
Yoo F, Jung HJ, Oh KW (2021) Motivators and barriers for buying intention of upcycled fashion products in China. Sustainability 13:2584. ARTN 2584. https://doi.org/10.3390/su13052584

Young S (2019) The real cost of your clothes: these are the fabrics with the best and worst environmental impact. Independent, Available from https://www.independent.co.uk/life-style/fashion/fabrics-envir onment-fast-fashion-eco-friendly-pollution-waste-polyester-cottonfur-recycle-a8963921.html. Accessed 01 Aug 2020
Publisher's Note Springer Nature remains neutral with regard to jurisdictional claims in published maps and institutional affiliations. 